\title{
Entrevista jornalística confissão e as neoconfissões na mídia brasileira
}

Beatriz Marocco ${ }^{1}$

Resumo: Este texto focaliza a entrevista como uma prática jornalística confessional. Tal objeto configura um percurso epistemológico que associa o pensamento foucaultiano sobre a confissão à "neoconfissão", assim como essa foi descrita por E. Morin (2000). No âmbito discursivo aparecem os papéis e as funções da dupla jornalista/que interroga e fonte/que confessa, como se a fonte estivesse diante de uma autoridade investida para tal fim. Três entrevistas, que formam um pequeno corpus, selecionado a partir do acompanhamento diário de diferentes mídias, provocaram insights úteis, que apresentamos neste artigo, para a constituição de uma tipologia que vem ao encontro dessa relação e nos permite avançar em direção a um rompimento definitivo com o ritual da confissão nos novos ambientes digitais.

Palavras-chave: entrevista, confissão, neoconfissão, jornalismo, verdade.

Abstract: This article focuses on the interview as a journalistic practice of confession. Such object constitutes an epistemological route that approaches the foucaultian conception of confession (Foucault, 1998) to the "neo-confession" described by E. Morin (2000). On the discursive scope they appear the roles and functions of the journalist/ who questions and the source/who confesses, as if during the interview the source was face-to-face with an authority empowered to this objective. Three interviews, which formed the little corpus, have been selected in different media and might provoke useful insights that resulted a typology of the relationship journalist/source and can advance to a definitive rupture with the ritual of confession inside the new digital environment.

Keywords: interview, confession, neo-confession, journalism, truth. 
Quando o jornalismo brasileiro, por volta do século XIX, deixou de ser o "campo de batalha de políticos, partidos, movimentos sociais, sindicatos e agremiações", que queriam publicar suas posições e entrar na "quermesse de opiniões", os jornais se aproximaram das fontes de informação para dar consistência discursiva à imagem de público imparcial que essas poderiam representar (MARCONDES FILHO, 2000, p. 110). A fala testemunhal, as versões de fontes conflitantes e a produção de efeitos de real e de impessoalidade narrativa, entre outras estratégias, sinalizaram a emergência de um campo de tensões no âmbito narrativo. Nos jornais, o narrador não deixaria mais a sua marca, como a mão do oleiro deixava na argila do vaso (BENJAMIN, 1996, p. 205), nem poderia esquecer-se de flexionar os verbos dicendi à sombra das fontes de informação, grandes marcadores do império da entrevista e da imparcialidade.

Naquele momento, descolar-se das administrações públicas, dos partidos políticos e da literatura, desvinculando o comportamento do jornalista da opinião e da ficção, dá certa autonomia ao jornalismo, na medida em que o que emana da fonte é concebido a priori como o relato de uma informação da esfera do público. Nesse novo regime discursivo, característico do paradigma da "objetividade", o jornalista desaparecerá como sujeito que fala de si, de sua própria experiência, e que dá conselhos, deixando esse vazio, que havia preenchido com outros parceiros até o início do século passado, para a voz das fontes de informação (BENJAMIN, 1996, p. 202; MARCONDES FILHO, 2000, p. 110-111).

A produção do verdadeiro ocupa o centro desse novo regime discursivo que solda o jornalista à fonte. Nesse sentido, a colocação do testemunho da fonte em discurso e a associação dessas vozes que emanam do público em geral à imparcialidade que conferem ao jornalismo são duas peças de um mesmo dispositivo que abriga a enunciação verídica na entrevista jornalística. Nela, jornalista e fonte vivem uma relação assimétrica no âmbito das práticas: o primeiro não é simplesmente um interlocutor, um parceiro, 
mas a instância de poder que requer a verdade e lhe dá consistência material, com a sua divulgação. No exercício do jornalismo e na atualização das práticas reconhecidas como jornalísticas, o jornalista seleciona, avalia, dá acesso a quem pode ou não falar em nome do público. O jornalista promete modificações intrínsecas e efeitos virtuais ou reais (certo capital simbólico, poder-se-ia contrastar) para quem se submete ao processo: sucesso, julgamento, execração pública ou absolvição. Ora, a colocação da verdade em discurso, nos termos da entrevista, além de alicerçar o processo de epistemologização do jornalismo, no trânsito histórico do que se entendia por jornalismo partidário à imprensa industrial, ecoa nas práticas jornalísticas o procedimento milenar da confissão, assim como esse foi descrito por Foucault:

A confissão é um ritual do discurso onde o sujeito que fala coincide com o sujeito do enunciado; é, também, um ritual que se desenrola numa relação de poder, pois não se confessa sem a presença ao menos virtual de um parceiro, que não é simplesmente o interlocutor, mas a instância que requer a confissão, impõe-na, avalia-a e intervém para julgar, punir, perdoar, consolar, reconciliar; um ritual onde a verdade é autenticada pelos obstáculos e as resistências que teve de suprimir para poder manifestar-se; enfim, um ritual onde a enunciação em si, independentemente de suas circunstâncias externas, produz em quem a articula modificações intrínsecas: inocenta-o, resgata-o, purifica-o, livra-o de suas faltas, libera-o, promete-Ihe a salvação (1993, p. 61).

A confissão se disseminou em rituais probatórios, científicos e de demonstração como uma das técnicas mais eficientes para produzir a verdade e está "tão profundamente incorporada a nós, que não a percebemos mais como efeito de um poder que nos coage" (FOUCAULT, 1993, p. 59). O homem no Ocidente, afirmou Foucault, "tornou-se um animal confidente" (1993, p. 59).

A confissão difundiu amplamente seus efeitos: na justiça, na medicina, na pedagogia, nas relações familiares, nas relações amorosas, na esfera mais cotidiana e nos ritos mais solenes: confessam-se os crimes, os pecados, os pensamentos e os desejos, confessam-se passado e sonhos, confessa-se a infância; confessam-se as próprias doenças e misérias (...) confessa-se em público, em particular (FOUCAULT, 1993, p. 59). 
Em sua inscrição nas práticas jornalísticas, a confissão expõe uma face disciplinar, por ser ali que os procedimentos de individuação pelo poder jornalístico deslizarão da esfera do particular, assim como ocorre no confessionário cristão ou no divã, ao confessionário público. Há, também, um estreito parentesco interdisciplinar da prática jornalística com a cristã, em que o confessor pretende obter de quem confessa uma verdade sobre o pecado, com a prática da polícia, em que o policial espera ouvir a verdade sobre um crime, ou a da psicanálise, em que o especialista escava certa verdade possível no inconsciente do paciente. Em diferentes posições, o jornalista espera da fonte, na sua condição de testemunha, ora que emane uma verdade sobre os acontecimentos, ora que revele o que esconde, tenha essa informação origem no cotidiano da vida ordinária ou na própria alma humana, e que essa verdade se multiplique ao público em geral.

Duas derivações já foram inauguradas para dar seqüência a um pensamento sobre a existência e o funcionamento da confissão no âmbito jornalístico. A primeira delas, originada na sociologia de E. Morin, alicerça a "neoconfissão", que abriga as manifestações contemporâneas de um tipo de entrevista jornalística próxima da psicologia social: nesse caso, mais do que recolher informações, a entrevista poderá liberar energia afetiva em seus aprofundamentos e constituirse num "strip-tease da alma" (2000, p. 216, 218-219). Na segunda derivação, traçada mais recentemente, o pesquisador canadense C. Dent (2008) sugere que os jornalistas são "confessores do público". No contexto das ideias foucaultianas de confissão, isso significa que os jornalistas são uma autoridade que exige a confissão, a prescreve e a aprecia, intervindo para julgar, punir, esquecer, consolar e reconciliar. Ao fazer perguntas, um jornalista pode pedir, prescrever e apreciar as palavras da sua fonte, e a inclusão delas nas notícias pode significar validação e reconhecimento da confissão. Dent realizou entrevistas com 27 jornalistas australianos para chegar a essas conclusões, que reconheceram no âmbito das práticas a idéia, que circula na sociedade e chegou a ser expressa pelo ex-presidente George Bush, de que os jornalistas "veneram o altar da confissão pública" (DENT, 2008, p. 215). 
Seguindo na primeira direção, na medida em que nos interessa verificar como a confissão se apresenta no gênero entrevista, formamos um pequeno corpus para observação e análise, resultante do acompanhamento da mídia brasileira nos últimos anos. Duas entrevistas midiatizadas respectivamente em Veja, revista de informação semanal de maior tiragem no Brasil, e no programa dominical Fantástico, na Rede Globo de Televisão, visto por cerca de 80 milhões de pessoas, nos parecem exemplares da inscrição da confissão nas práticas jornalísticas sob novas formas midiáticas. Na sequência, um terceiro exemplar, recolhido do blog de língua inglesa PostSecret anuncia o que nos parece ser um rompimento definitivo com o ritual da confissão, em seu parentesco com as ações arcanas de ascesis descritas por Foucault (1999) em "A escritura de si". Nele, a figura do entrevistador que faz perguntas desaparece; é o indivíduo, em um exercício voluntário e solitário, que trata de provocar a coincidência entre o olhar do outro e o olhar que dirige sobre si mesmo para avaliar as suas ações cotidianas e elaborar a própria experiência.

\section{Neoconfissão}

A "neoconfissão", assim como essa foi pensada por E. Morin, reflete um tipo de entrevista em que o entrevistado abandona a superficialidade da informação para realizar um mergulho no interior de si mesmo. Nesses termos, a neoconfissão ecoa práticas jornalísticas, ou um modo de objetivação jornalística, apoiado na "busca da verdade", central para a existência da formação discursiva. Entretanto, o que é materializado como resultado desse "mergulho" naturalmente excede o nível informativo, o que situa a entrevista em uma zona de indeterminação disciplinar, fronteiriça à psicologia social. No seu interior, o entrevistador busca a verdade, mas em seu intento rompe com a objetividade jornalística: pode emocionar-se, julgar, punir, consolar e reconciliar. O entrevistado poderá não permanecer na superfície de si mesmo; lança-se, deliberadamente ou não, num mergulho interior. Segundo Morin, a "entrevista-mergulho" é continente de sua própria ambivalência: 


\begin{abstract}
Toda confissão pode ser considerada como um strip-tease da alma para chamar a atenção da libido psicológica do espectador, quer dizer, pode ser objeto de uma manipulação espetacular; mas, ao mesmo tempo, toda confissão vai muito mais longe, muito mais profundo que todas as relações humanas superficiais e lamentáveis da vida cotidiana... (2000, p. 218-219).
\end{abstract}

Não importaria, em muitos casos, qualquer "verdade" - a "verdade informativa", inclusive, ou a quase-mentira que flerta com a literatura - , mas a necessidade de os espectadores entrarem em contato, de alguma forma, com o "eu privado" como a própria expressão do "eu", seja através de sexo, crimes ou outros segredos. Poder-se-ia dizer, ainda, que, na neoconfissão, há interlocutores próprios do discurso jornalístico; entrevistado e entrevistador dialogam sobre as coisas do cotidiano, revelam-se opositores ou parceiros e serão lidos pelo público. Ante a premissa de que a entrevista será publicizada, em busca de uma confissão, o jornalista poderá se fundir à figura do juiz ou à figura do policial, ou a ambas, distanciando-se de certo modo do psicanalista em função das condições das práticas psicanalíticas e da lei de silêncio que as cerca -, produzindo, com isso, práticas jornalísticas singulares que excedem as leis da formação discursiva, e uma figura de jornalista singular, efeito do poder midiático e objeto ambíguo de relações de poder sutis, móveis e dispersas no campo social. No caso concreto, que vamos examinar a seguir, os discursos da justiça criminal, da psiquiatria e do jornalismo se conjugariam em rede. 


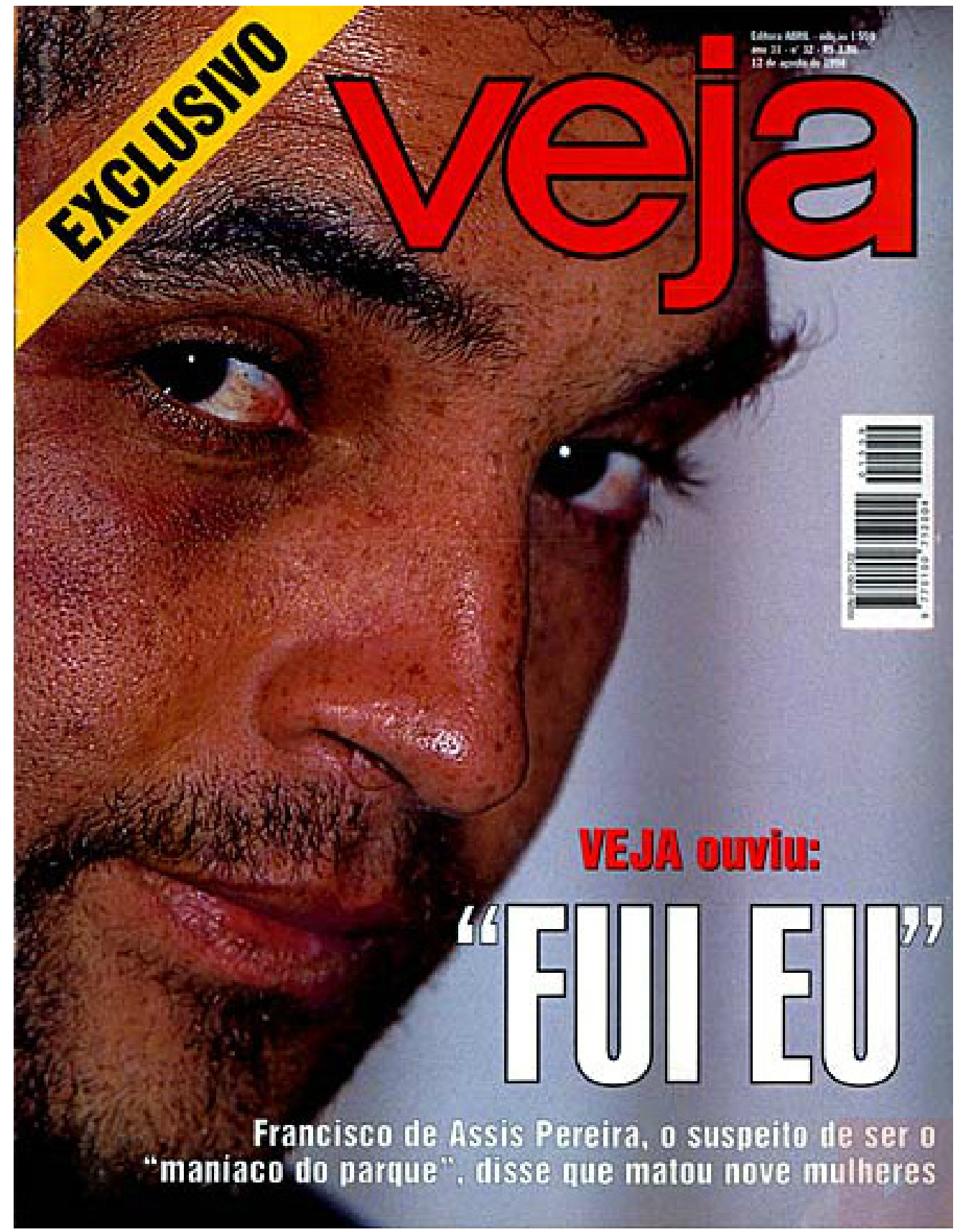

Veja, ago. 1998

A sofreguidão com que Francisco de Assis Pereira, o "maníaco do parque", confessa o assassinato de nove mulheres evidencia a relação estreita do jornalismo com a técnica da confissão. No início, a jornalista tenta uma breve aproximação, com perguntas diretas sobre ele se conhecia duas vítimas, Thayná e Elisângela - às quais responde com negativas. Depois, quando 
enfrenta uma questão sobre o seu desempenho sexual, o entrevistado parece menos rígido e mais fragilizado. Concorda que havia feito sexo anal com "alguma de suas vítimas" (expressão postulada pela jornalista) para, então, "em ritmo frenético", admitir todos os crimes que não havia confessado nem à polícia e assumir a confissão diante da jornalista (do público de Veja): "Fui eu"; aí, então, conta como construiu as suas próprias armas de matar, como as empregou e, por fim, passada a confissão, ele elabora, modifica o ritmo e se dá conta que teve com a repórter uma relação que nunca teve com a mãe, evocando para o leitor, além da existência do fantasma do divã entre eles, uma figura arcana: de Pierre Rivière, o camponês francês de cerca de 20 anos "que dizia mal saber ler e escrever e que tinha empreendido, durante sua prisão preventiva, a tarefa de dar detalhes e explicação sobre seu crime: o assassinato de sua mãe, de sua irmã e de seu irmão" (FOUCAULT, 1991, p. IX-X). No memorial, Rivière disse que nunca tinha conseguido entender como a mãe maltratara tanto o pai, que havia fabricado na sua infância uma pequena arma para matar pássaros, o calibene. Mais do que isso, entre os dois, Francisco e Rivière, havia os olhos avermelhados descritos por Foucault e surpreendidos em toda a sua intensidade pelo fotógrafo de Veja: "Fomos subjugados pelo parricida dos olhos avermelhados" (FOUCAULT, 1991, p. XIV).

Veja, na edição de agosto de 1998, publica a neoconfissão de Francisco de Assis Pereira:

- Francisco, você conhece Thayná?

- Thayná? Thayná... Não conheço.

- E Elisângela, você conheceu alguma?

- Não.

- Selma?

- Não. Também não.

- E você fez sexo anal com alguma de suas vítimas?

- Fiz, com algumas.

Pausa. Surpresa. O diálogo continua, em ritmo menos frenético:

- Você matou algumas daquelas mulheres, Francisco?

- Matei.

- Quais? 
- Todas.

- Quantas mulheres você matou?

- Nove.

- Você matou Isadora?

- Matei. Fui eu.

Francisco demorou frações de segundos para reconhecer que matou Isadora Fraenkel, 18 anos, uma bonita garota de classe média paulistana que no dia 10 de fevereiro saiu de casa para ir à aula de inglês e desapareceu. O silêncio que veio depois da confissão durou pelo menos um minuto.

- Como você matava as moças?

- Com o cadarço dos sapatos ou com uma cordinha que às vezes eu levava na pochete. Eu dava um jeito.

Outra pausa, alguns pigarros. É o próprio Francisco quem volta a falar. A voz sai serena, com um tom de constatação:

- Nunca contei isso pra ninguém, nem pra minha mãe. Eu tenho um lado ruim dentro de mim. É uma coisa feia, perversa, que eu não consigo controlar. Tenho pesadelos, sonho com coisas terríveis. Acordo todo suado. Tinha noite que não saía de casa porque sabia que na rua ia querer fazer de novo, não ia me segurar. Deito e rezo, pra tentar me controlar.

\section{O segredo roubado}

Em torno do assassinato do casal Manfred e Marísia von Richthöfen, foi produzida uma miríade de microrrelatos jornalísticos de origem, forma, organização e função diferentes daqueles dos advogados, dos assassinos, da família. Todos eles, em sua heterogeneidade, se referem a um mesmo acontecimento, e não formam uma obra nem um texto, mas uma luta singular, uma batalha de discursos e através de discursos: os advogados travam uma batalha entre eles, a respeito das perícias médicas, da natureza do delito, da liberdade provisória, do caráter dos assassinos, do uso das circunstâncias atenuantes ou da qualificação do crime. Daniel Cravinhos, um dos assassinos, ora se diz apaixonado por Suzane von Richthöfen, ora, com o irmão Cristian, acusa Suzane de ser mentora do assassinato dos próprios pais, ora ambos fazem apologia à impunidade. 
Por fim, as histórias de Suzane Louise von Richthöfen. Um grande conjunto de ciladas armadas contra nós, leitores, em que Suzane se manifesta fria, calculista e impiedosa (descrição do delegado Domingos de Paula Neto, que dirigia o Departamento de Homicídios e Proteção à Pessoa de São Paulo quando ocorreu o duplo assassinato de Manfred e Marísia, no dia 31 de novembro de 2002), ou se comporta como uma criança pequena, falando baixo, com voz infantil, apresentando-se como personagem vitimizada, carente, merecedora de pena. Diante da mídia, a esses discursos somam-se os pequenos detalhes que vão dar a Suzane o brilho intenso e fugaz dos indivíduos que se tornam notícia somente por suas desgraças: a carta escrita na prisão para os pais do ex-namorado, o álbum de fotos da infância, em cenas familiares, a imagem atrás das grades ou o corpo exposto ao lado do namorado em biquíni sumário.

A tecnologia virá acrescentar à neoconfissão um instrumento inusitado, que se agrega à câmera, ao microfone aberto e ao potencial "extralúcido" que ambos possuem e que pode, segundo Morin, "induzir os entrevistados a dizer a verdade"2 (2000, p. 221): algo que não havia sido compartilhado nem com a polícia nem com os jornalistas, muito menos conosco, leitores, e que pertence à esfera do íntimo do assassino e à estratégia de defesa. O mesmo microfone que, conforme o cânon determina, é para ser utilizado na entrevista e que deveria ter sido desligado na ausência da jornalista (entrevistadora) vai gravar, à revelia da assassina (entrevistada), dois fragmentos de conversa íntima entre ela, o seu procurador e o seu advogado, colocando em evidência a existência de um elemento de fora das práticas jornalísticas, que não pertence à verdade jornalística, mesmo quando a entrevista se sustenta na neoconfissão, assim como essa foi pensada por Morin (2000, p. 218).

No relato da entrevista com Susane von Richthöfen, que foi levada ao ar no programa Fantástico (9 de abril de 2006), os microfones abertos da emissora, sem que se formasse a figura da entrevista jornalística, ou seja, sem a presença da entrevistadora e sem que a entrevistada soubesse que estava lançando sua mensagem ao mundo, deixam aparecer dois fragmentos de conversa que 
colocam em evidência a existência do "segredo" (que permanece escondido de nós no próprio seio da neoconfissão). Quando os advogados de Suzane lhe sugerem (presume-se que sem saber que estão sendo gravados) que chore e se comova, deixam exposto o que seria uma forma de lacuna admitida pelo saber jornalístico, em sua "busca da verdade", uma lacuna que nos é imposta - a todos nós, espectadores - e que, em função das condições tecnológicas, rompe com as normas jornalísticas e passa a fazer parte do sistema - não mais de uma estratégia que move a assassina a falar à mesma mídia. O que estava reservado a nós pela assassina era somente a encenação de tristeza de quem ocupa o centro da representação e parece estar em busca de um melhor julgamento. Os elementos que materializaram a imagem que Suzane gostaria que arquivássemos dela poderiam ter sido, como o foram, quantificados (o número de vezes que enxugou os olhos ou os desviou para o seu tutor), enquanto as imagens técnicas de sua expressão e do seu corpo sinalizavam outras coisas sobre ela, expondo ao espectador mais atento que Suzane frequentemente desviava o olhar da câmera, parecendo evitar-nos. Uma contabilidade precisa de pequenas evidências de uma farsa, reconhecidas na mesma semana por uma jornalista de Veja (12 de abril de 2006), poderia por si mesma instaurar outro centro que iria organizar o quadro, conforme a atenção do espectador divagasse para fora do que estava sendo mostrado.

Ao contrário da neoconfissão - que é reconhecida pelo saber jornalístico e supõe uma hierarquia entre entrevistador e entrevistado e uma sequência interrogatório/confissão, para que o entrevistado mergulhe em sua intimidade -, agora o entrevistado, além de se submeter ao jogo com o entrevistador, vai ser submetido a um exercício de insubmissão ao que está prescrito pelo gênero, que será regulado e controlado não mais pela figura (controlada e controladora) do jornalista, mas sim pela do produtor, ou se precaver contra a possibilidade de ser surpreendido por esse fenômeno de omnivisibilidade que ainda não está codificado pelo jornalismo e que está ocorrendo no bojo das práticas. 


\section{Confissões eletrônicas}

A recente emergência das mídias digitais subverte ainda mais as figuras do produtor, que no exemplo anterior ocupou a cena na ausência do jornalista, e da fonte. Com isso, a sequência interrogatório/confissão, que era constitutiva da prática de entrevista jornalística, será deslocada para uma tríade: um sistema que não interfere no conteúdo, apenas fornece um modelo; um sujeito que escreve sobre si mesmo; e um olhar possível e indeterminado.

Em outras palavras: da internet emerge uma espécie de contradiscurso, que parece instalar-se no exterior da entrevista, fundando um lugar de não sujeição dos indivíduos, um lugar de não objetividade, que instala uma estética da emoção - seja riso, seja ironia, seja tristeza, seja deboche. O blog PostSecret é exemplar nesse tipo de produção que contrasta a forma de objetivação, que transforma os seres humanos em sujeitos da entrevista jornalística, com outras práticas de produção da verdade em dispositivos comunicacionais.

Poder-se-ia dizer que se trata de um ritual para produção da verdade que se desvia do paradigma da objetividade cristalizada pelo campo do jornalismo e que poderia ser comparado às técnicas da cultura filosófica de si com o uso da escritura, em que o indivíduo pratica um exercício voluntário de introspecção, anota os seus atos para um possível interlocutor e, fazendo isso, elabora a sua experiência e se prepara para enfrentar o real. Ao contrário da confissão e das derivações que vimos anteriormente - que são reguladas pelo jornalismo e supõem uma hierarquia entre quem entrevista e quem é entrevistado - , no blog digital, quem escreve, escreve porque quer, quando quer e como deseja para outro indivíduo, que, em um momento distinto, vai desencadear um exercício voluntário de leitura.

Há nesse jogo certo parentesco com as ações arcanas de "escritura de si" descritas por Foucault (1999), em que os atos e os impulsos da alma são escritos para si mesmo, como se o indivíduo em sua solidão estivesse fazendo revelações a outro. A anotação das ações e dos pensamentos era recomendada 
como forma de evitar o pecado, pois escrever significava estar diante de uma testemunha, e não se peca diante de testemunhas. Nesse sentido, esse exercício escrito da ordem dos movimentos interiores da alma poderia ser uma arma de combate espiritual, para a produção da verdade e para evitar o pecado. Foucault localizou-o em documentos dos séculos I e II, no exterior de duas formas utilizadas com outros fins: os hypomnemata - cadernos individuais que serviam de dispositivos de memória - e a correspondência (1999, p. 289-305).

O arquivo de cartões postais do blog em posts como os que seguem parece desviar a prática confessional da entrevista para um exercício solitário de ascesis, marcado pela exposição da experiência íntima que se faz dizível. Além disso, e como um avanço desse tipo de produção, é possível dizer que tal forma revela a interiorização de valores e experiências que se descolam da ordem social e jornalística. Não há conexão, igualmente, com o que se chama "atualidade" na redução que o jornalismo faz dela a uma "rapsódia de acontecimentos divertidos" (BOURDIEU, 1998, p. 100). O que é visível nas imagens nos aproxima da ficção e é por essa via que nos afeta e parece contribuir de modo singular para o desencadeamento de um exercício de introspecção de quem deseje, nesse ambiente digital compartilhar uma experiência simultaneamente íntima e onírica.

Não há, portanto, no blog, uma relação de autoridade, que era característica na neoconfissão e se insinuava com o produtor, à revelia de Susane von Richthöfen, mas uma relação de cumplicidade, que beira o sonho de cada um de nós com um possível leitor. Nesse sentido, o site projeta para o exterior do espaço midiático o ritual que supõe a existência de uma autoridade e de uma interioridade a ser dita e controlada, no caso do jornalismo, por sua condição de discurso que diz a verdade do mundo e pela figura do entrevistador que o sustenta e reproduz. 

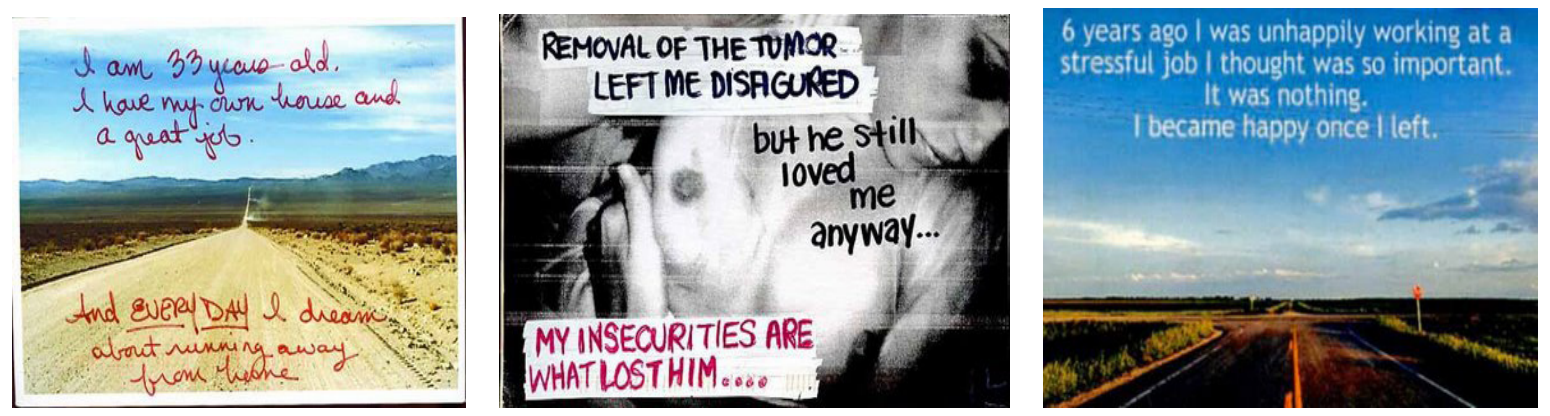

\section{Conclusão}

Ao final, podemos constatar que a entrevista incorporou o ritual da confissão no projeto arcano de "busca da verdade", que deu a autonomia de disciplina ao jornalismo (MARCONDES FILHO, 2000; DENT, 2008); foi vazada em sua objetividade por outras disciplinas no modo de "entrevista-mergulho" ou "neoconfissão" (MORIN, 2000); e, mais recentemente, está deixando emergir elementos exógenos às figuras e às ferramentas clássicas da confissão adaptadas e perpetuadas pela imprensa.

No estudo que realizamos a partir do que disse Morin, localizamos:

1. Primeiramente, formou-se no âmbito da neoconfissão uma zona transdisciplinar em que as figuras clássicas do entrevistado e do entrevistador se embaralharam às figuras do juiz, do policial e do psicanalista. Vislumbrase, aí, estreito parentesco com a "entrevista-mergulho", considerada por Morin "um strip-tease da alma para chamar a atenção da libido psicológica do espectador" (2000, p. 218).

2. Com as mídias eletrônicas, verificou-se que a produção da verdade pode ser estendida a elementos estranhos à entrevista jornalística (assim como essa foi concebida no interior do paradigma da objetividade). A relação de autoridade entre o jornalista que escuta (instância de dominação) e aquele que confessa (instância de submissão) vai se desviar da norma. O jornalista se ausentará e, em sua ausência, o microfone aberto dá a ver as linhas que atravessam a profundidade do quadro e que foram parcialmente obscurecidas 
na entrevista, provocando uma dilatação do relato graças à figura técnica do produtor, que domina a tecnologia, embora não interfira na concepção do gênero e que forma com os dois elementos constitutivos da neoconfissão uma relação triádica - jornalista, fonte e produtor.

3. O "segredo roubado" pelos microfones poderia ser interpretado: a) Singelamente como um discurso vital para todos nós e para a justiça, na medida em que traz à luz uma peça importante para estabelecer a verdade sobre Susane; b) Como a evidência de uma tensão na esfera da confissão entre o "eu privado" que será socializado na entrevista e o "eu interior" de cada um dos personagens que permanecerá invisível aos nossos olhos na materialidade discursiva; c) Como um elemento do "eu interior" que rompe com o regime discursivo inerente ao modo de produção da mídia e tira da sombra um elemento estranho à representação midiática.

4. O segredo que veio à superfície com o sumiço do jornalista e com o avanço da ferramenta e da figura do produtor, sintoma de ausência de um dos polos constitutivos da entrevista, será banalizado. Na internet, a ausência do jornalista é quase uma lei, ou uma das leis de um espaço que se rebela contra a disciplina da velha imprensa. Há que se pensar com mais vagar nessa diferença do exercício de construção de si em ambiente digital - em relação à neoconfissão. Os usuários que buscam a máquina rompem com uma relação de hierarquia e autoridade própria da disciplina; por outro lado, os usuários comprometem-se com a tecnologia em um nível corporal, mais intensamente do que no caso de assistir à TV ou ler o jornal; e, mais do que em outras mídias, eles aceitam ser controlados pela máquina. Esse é um aspecto que merece ser explorado de um modo mais complexo. 


\section{Referências}

BARTHES, R. Elementos de semiologia. São Paulo: Cultrix, 1964.

BENJAMIN, W. Obras completas. Magia e técnica, arte e política. Vol. I. São Paulo: Brasiliense, 1996.

DENT, C. 'Journalists are the confessors of the public', says one Foucaultian. Journalism, n. 9, 2008.

FOUCAULT, M. "La escritura de si". In: A. GABILONDO (Ed.). Michel Foucault, estética, ética, e hermenéutica. Barcelona: Paidós, 1999.

. "Verdad y poder". In: J. VARELA; F. ALVAREZ-URÍA (Ed.). Michel Foucault, estrategias de poder. Barcelona: Paidós, 2000.

História da sexualidade. A vontade de saber. Rio de Janeiro: Graal, 1993.

. Eu, Pierre Rivière, que degolei minha mãe, minha irmã e meu irmão. Rio de Janeiro: Graal, 1991.

LANDOWSKI, E. A sociedade refletida: ensaios de sociossemiótica. São Paulo: Pontes, 1992.

MARCONDES FILHO, C. A saga dos cães perdidos. São Paulo: Hacker, 2000.

MAROCCO, B. "A zona de sombra dos conceitos de agenda-setting e gatekeeper". In: Contracampo. Rio de Janeiro: UFF, v. 12, 2005.

MORIN, E. Sociologia. Madrid: Tecnos, 2000.

\section{Revistas}

VEJA. Ano 31, n. 32, 12 ago. 98.

VEJA. Ano 39, n. 14, 12 abril 2006.

\section{Sites consultados}

PostSecret. Disponível em: <http://postsecret.blogspot.com/>. Acesso em: 30 set. 2006 
1 Professora do Programa de Pós-Graduação em Ciências da Comunicação da Universidade do Vale do Rio dos Sinos (Unisinos). Doutora em jornalismo pela Universidade Autônoma de Barcelona.

2 A câmera, assim como o microfone, incrementa a tendência à inibição e, igualmente, à exibição. Dispõe de um potencial "extralúcido" e pode induzir o entrevistado a dizer a verdade: "Isso pode se traduzir em uma comédia mentirosa, pois, quando está à beira da verdade é quando o indivíduo se lança vertiginosamente na fabulação" (MORIN, 2000, p. 221). 